Original scientific paper

\title{
A SIMULATION APPROACH FOR TRANSITION TO JIT PRODUCTION SYSTEM
}

\author{
Kilic, R. \& Erkayman, B. \\ Department of Industrial Engineering, Ataturk University, Erzurum, Turkey \\ E-Mail: raziyekilic@atauni.edu.tr, erkayman@atauni.edu.tr (" Corresponding author)
}

\begin{abstract}
Consumption is increasing day by day due to rapid developments in technology and increasing world population. Companies should review their production processes in order to keep up with the consumption rate and increase their competitiveness as well as profit margins. This research shows a case study of simulation application to improve solar panel manufacturing process. The aim is to achieve goals such as increasing system efficiency, reducing inventory and shortening delivery time. Efficient manufacturing process design may reduce work-in-process (WIP), waste, rework and faults, which may reduce the total number of products and yields an increase in the system cost. Inefficiency points were determined in the process based on the obtained observations of the manufacturing system. Various scenarios have been proposed to design such an efficient production system. According to the proposed scenarios, an increase in the utilization rates of machinery, personnel and the total number of final products has been achieved.

(Received in March 2021, accepted in June 2021. This paper was with the authors 1 month for 2 revisions.)
\end{abstract}

Key Words: Discrete Event Simulation (DES), Just-in-Time (JIT), Lean Manufacturing, Production Line Efficiency, Solar Panel Production

\section{INTRODUCTION}

Companies have been looking for a system in customer-oriented and globally competitive market approach, and at this point they have turned to 'lean manufacture' to improve their methods and make their operations more profitable. The aim of lean manufacture is to be sensitive to customer demand by reducing losses in the company. Lean manufacture aims to produce products and services as quickly as the customer wishes and at the lowest possible cost.

Just-in-time (JIT), which is one of the basic principles of lean manufacture, can bring a different perspective to a manufacturing system in a variety of applications. It makes an impact not just in manufacturing activities but in other areas, such as the production system, material procurement, storage, maintenance, engineering design, and sales and senior management because JIT production is a strategy that aims to improve work efficiency significantly and continuously by preventing and eliminating time and resource losses across the entire organization. The main purpose of JIT is to improve the quality, cost and delivery performance at the simultaneously by increasing the production speed and reducing the flow time. It aims to reduce inventory, operating and waiting times of machines, and operations that do not create added value. In order to reduce work-in-process (WIP) inventory during production, to increase the number of ready for shipment products and to increase the operational efficiency, it is aimed to work with minimum inventory by applying the JIT method. With the JIT application, significant gains are achieved in the finished product warehouse, raw material warehouse and during production. It is also aimed to increase the total amount of finished products by shortening the deadline times, the product delivery time and preventing excessive raw material inventory, as well as increasing the production speed, the use of machinery and personnel, and decreasing the amount of WIP inventory.

Although information is not a tangible asset, it is an important resource for businesses due to its unique characteristics. The use of information depends on the knowledge of workers in a company. In businesses, the tacit knowledge needs to be transformed into explicit 
knowledge [1]. Simulation models are used to provide evidence for hypotheses about the real world and to obtain new knowledge. Simulation models not only serve to increase the computational power of people, but also serve as community knowledge integration, in which the implications (a distillation) of collective knowledge can be discovered [2]. It allows users to analyse the behaviour of the system with a good simulation model and to answer all questions encountered in production.

This study aims to present comprehensive real-time, data-driven approach to detect bottlenecks and WIP inventory using real-time data from machines and personnel. Data on processing times were collected by observing the machine/personnel at different times and shifts regarding the operations performed by each machine/personnel on the product. A realtime bottleneck control method was developed using online measurable data, such as production line blockage and idle information to monitor system performance in real time and achieve sustainable production benefits based on continuous production improvement. Time measurements were made in the company to investigate the machine and personnel usage rates. The time between the start and the end of the work was recorded for each machine and for personnel. This process was repeated at different times during different shifts. According to the observed results, factors such as whether the machines are maintained on time, the machine performance after failure, the ability of the operator to perceive a problem with the machine or the product, and the personnel motivation to work on that day all affect the duration of the work, the quality and the total performance of the system. Therefore, the measurements did not always yield the same results, so they were averaged.

These measurement results were analysed using the simulation software program called Arena and used to determine which distribution type fitted the processes. These distributions were then used for modelling in the Arena software. In this way, bottlenecks were determined, and by adding conveyors, machinery and personnel at those bottlenecks, and removing conveyors, machinery and personnel from stages where inefficiency was identified. Hence, this ensured that the line was balanced. For this purpose, the number of products and machinepersonnel utilization rates were examined by simulating the current production system. The company's current production line was modelled in the Arena software. Verified and validated models (VVM) were designed according to the processes that had a bottleneck or were inefficient, according to the results and the observations made in the company. With the VVM, new simulation approaches were created in which stations were used more efficiently. Meaningful results were obtained by comparing the number of machines and machine usage rates in the current system against the VVM.

\section{LITERATURE SURVEY}

El-Khalil [3] performed a study to detect, analyse, solve and reduce inefficiencies in a vehicle assembly system using discrete simulation modelling. Kliment et al. [4] proposed using simulation for improving the efficiency and quality of products in the production process in the food industry. Kłos and Patalas-Maliszewska [5] conducted an analysis using computer simulation to model the efficiency of production processes, provide product life analyses of the production line and address the issue of intermediate buffer allocation. Lee et al. [6] focused on optimizing efficiency in semiconductor wafer manufacture. Tvrdon and Fedorko [7] presented a framework for using dynamic simulation in production systems design and successfully applied to a real-life project of innovation of a production system in a pressing shop. Abolhassani et al. [8] developed the reliable and hybrid model, hours-per-vehicle, the most popular efficiency measurement system in the automotive industry. Jakubovskis [9] created a model aimed at examining the relationship between the overall capacity utilization rates and the rate of flexible technologies obtained under uncertain demand conditions by using an 
optimization algorithm. Li [10] proposed a new data-oriented bottleneck detection method based on mathematical evidence for mass production systems. Onofrejova et al. [11] proposed the simulation model for production of fireplaces, considering production key parametersproductivity and throughput. Yang et al. [12] proposed to efficiently optimize a changed production layout and configuration using a modelling and optimization method based on DES. Tiacci [13] presented a novel approach combining simulation techniques and a genetic algorithm approach for mixed-model assembly line balancing problems with stochastic task times, workstations and buffers between parallel workstations. Li et al. [14] aimed overcome the defects of bottleneck recognition and scheduling optimization in production line through simulation. Supsomboon and Vajasuvimon [15] proposed a simulation model for a workshop manufacturing process in machine tool manufacturing. The experimental results of the study showed that group technology, facility layout, business growth and capacity expansion played important roles in reducing operating cost and increasing average employee utilization and thus, increasing the efficiency of the system. Pekarcikova et al. [16] analysed the productivity and efficiency of production and logistics flows according to the current situation using modelling and simulation, and then optimization using software support were suggested. Takakuwa et al. [17] aimed for their students perform work measurement studies including time study, process design, such as line balancing, and execute simulation experiments. Supsomboon and Varodhomwathana [18] investigated the use of simulation to efficient production process design for automotive part production. Das [19] suggested an approach to integrate lean system applications with the design and planning model of a supply chain to improve the sustainability performance of the entire business. Ledón et al. [20] investigated current research on the relationship between lean manufacturing and business performance. Kovács [21] aimed to minimize the material workflow, to reduce the transport distance of materials, the material handling cost and the space used for assembly with the lean method and facility layout design method. Erkayman [22] proposed an approach combining company resource planning systems and JIT manufacturing system methodologies. Gundogar et al. [23] investigated the line interruption and efficiency problem in an automotive factory operating with a JIT manufacturing system using the root cause analysis method.

\section{METHODOLOGY}

Lean manufacture is a method that every business should definitely adopt if it wants to increase its production, increase efficiency and decrease the rate at which waste is produced. Decreasing the rate at which waste is produced and increasing the efficiency means decreasing the costs. The decrease in costs means that profits will increase. Therefore, lean manufacturing is a must for efficiency. Efficiency in the company is considered as the effective use of resources such as labour force, machine usage capacity, materials (raw materials and semi-finished products). Thanks to the effective use of these resources, they will provide benefits such as reduction in WIP, increase in machine utility use, indirect cost reduction and energy savings. The flow chart to be followed in the study is shown in Fig. 1.

\subsection{Improvement of system performance with JIT}

The core principles of JIT are eliminating waste, improving quality, increasing efficiency and ensuring the continuous improvement of products and manufacturing processes. An 'Inventoryfree manufacturing' application, which produces everything needed as required or 'Just in Time', covers both the key industry and sub-industry productions in lean manufacturing. Accordingly, in both key and sub-industry productions, all stages of manufacture (final product, finished parts used in the final product, parts processed in the manufacturing process, raw 
materials used in manufacturing) work completely without, or with minimal, inventory. The gains to be obtained by the application of JIT can be listed as follow:

In the finished product warehouse: product storage time will be less, product shipments will quicker, customers will be given a more accurate deadlines for delivery, less storage space will be needed for finished product.

In the raw material warehouse: excess raw material inventory will be prevented, the raw material cycle time will be shorter, less storage space will be needed for raw material, the potential of manufacturing products with the features desired by the customer will increase as there is no raw material held in stock, variability in customer demand will be responded to more quickly, procurement decisions will be made more accurately, the monetary resources not needed to pay for (excess) raw material purchase can be utilized in another way.

During manufacture: production speed will increase since semi-product will not have to wait during the production process, WIP will decrease, the usage rates of machines and labour will increase, expenses for machinery, personnel, energy and factory space will decrease, productivity will increase.

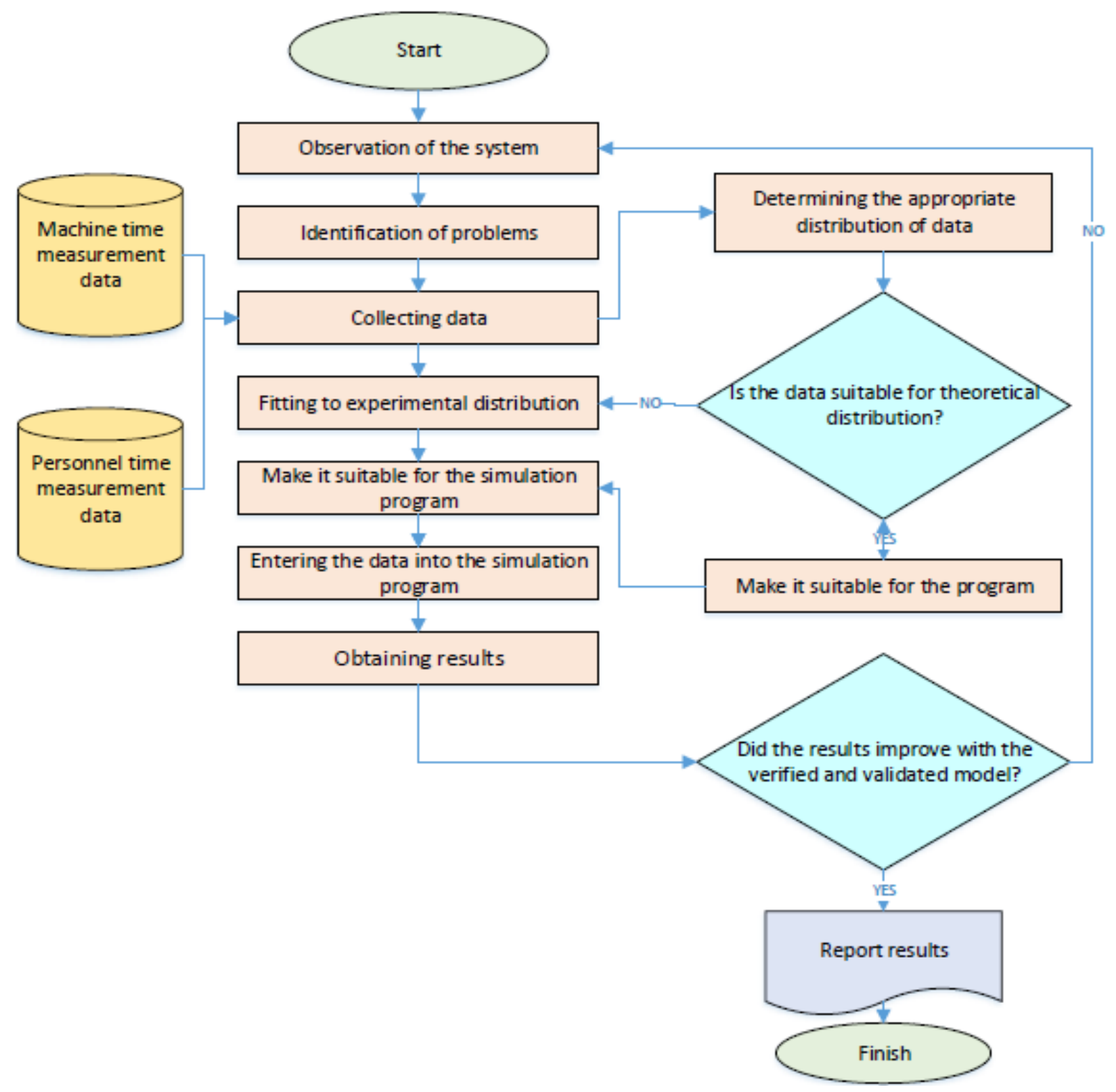

Figure 1: Workflow chart of the methodology. 


\subsection{Study of inventory reduction and unbalanced production lines}

Inventory means that production is happening ahead of time and there is more production than necessary. One of the biggest disadvantages of inventory is that it reduces the speed of capital conversion, and thus, profitability. Another negative side effect of inventory is related to 'opportunity costs'. Inventory also prevents the possibility of a company responding to customer demand, because the product in inventory needs to be used up first, i.e. sold, regardless of what the demand is, therefore customers can only buy those products. It also reduces the response speed to the customer demand. However, regardless of the stage of manufacture, 'wait' is a factor that adds no value to the product; moreover, it decreases productivity, increases costs, prolongs production times and is a type of waste.

In this study, a simulation method was used to detect WIP inventory in workstations where there was an imbalance in the production line. Simulation is one of the analytical tools used in the modelling and solution of complex systems. They are more successful compared to other analytical methods. In short, simulation is the imitation of the functioning of a system. Simulation is used in many application areas such as lean manufacturing, the design and analysis of production systems, assembly line balancing, labour planning etc.

\section{CASE STUDY}

The study was conducted at a photovoltaic solar panel production facility. Both machine and manpower were used during panel production. Processes where manpower was used intensely were the places where the inefficiency was highest, because the production speed and efficiency varied according to the knowledge and skill of the personnel. The productivity and capacities of workers caused uncertain application times for production tasks. Therefore, assigning the best employee for each job can significantly increase his/her productivity. Productivity is an important parameter to evaluate production performance.

Therefore, the company wanted to investigate whether the production line was balanced, and to increase production performance and maximize the number of products. The workflow of analysed system is shown in Fig. 2. The modelling of the workflow for the panel manufacturing company was made according to the current machine layout and with the current personnel. The company is a project-based manufacturer. Machine processing time, labour time and machine usage rate varied according to the type of product requested.

Machinery and conveyor systems were used intensively in this business. The starting point of the modelling was where glass entered the system. Here, a conveyor system transported the products to the next process. If the conveyor was full, queues formed in the system. It was observed that the queues formed mostly where processes were done with manpower and whose process times were variable. Also, since the conveyors had a certain carrying capacity, it prevented other processes from functioning.

In this study, observation-based data collection method was used during the data collection process. With the time study, data were created by recording machine and personnel processing times. Firstly, the manufacturing processes and workflows were observed, and then data were collected by measuring the time of processes. The production line was simulated in a computer environment with the results obtained from studies, including the investigation of production processes, determination of the production line workflow, examination of the current production line layout and time measurement studies. The Arena software was used to perform the simulation of the studied application.

The working times of the machines and personnel were recorded during simulation. It was then determined which distributions fitted these periods. Operations and statistical distribution table is shown in Table I. 

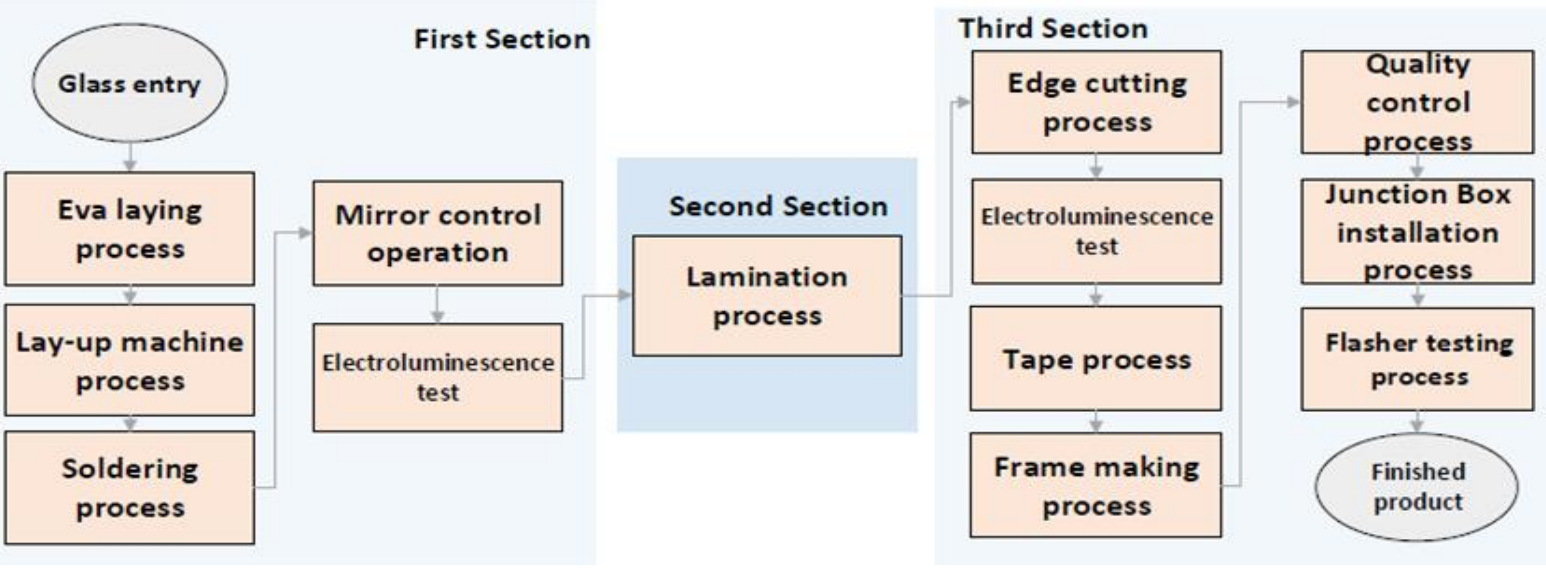

Figure 2: Workflow chart of solar panel production process.

Table I: Operations and statistical distributions table.

\begin{tabular}{|c|c|c|}
\hline Action Performed and Explanation & $\begin{array}{l}\text { Machine (M) } \\
\text { /Personnel (P) }\end{array}$ & Operation Duration/Distribution \\
\hline Glass load (Entrance of glass to conveyor system) & M & $40+\mathrm{EXPO}(6.52)$ \\
\hline EVA laying (Laying out EVA onto glass) & $P$ & $32+33 \operatorname{BETA}(0.398,0.582)$ \\
\hline $\begin{array}{l}\text { Lay-up process (Installing cell series on EVA-laid } \\
\text { glass) }\end{array}$ & M & $\begin{array}{l}\operatorname{NORM}(142,5.84) ; \operatorname{NORM}(205,20.5) ; \\
\operatorname{NORM}(222,16.1) ; \operatorname{NORM}(310,91.3)\end{array}$ \\
\hline Soldering (Soldering cell series inter-connecting) & $P$ & $\operatorname{NORM}(120,2.15)$ \\
\hline Mirror control (Control of cell series) & $\mathrm{P}$ & $\begin{array}{l}\text { 46.5+GAMM(1.63, } 2.97) \\
41.5+\operatorname{GAMM}(6.24,2.34)\end{array}$ \\
\hline $\begin{array}{l}\text { Electroluminescence-tester } 1 \text { (EL1) (Electrical } \\
\text { control of cell series) }\end{array}$ & $\mathrm{P}+\mathrm{M}$ & $\begin{array}{l}\text { 39.5+WEIB }(5.46,1.95) \\
39.5+\operatorname{WEIB}(4.89,1.25)\end{array}$ \\
\hline Lamination (Lamination of connected cell series) & M & $\operatorname{NORM}(1050,1.5)$ \\
\hline $\begin{array}{l}\text { Edge trimming (Cutting overflowing melted EVA } \\
\text { out of glass during lamination) }\end{array}$ & $\mathrm{P}$ & 7.5+WEIB $(3.61,1.6)$ \\
\hline $\begin{array}{l}\text { Electroluminescence-tester } 2 \text { (EL2) (Electrical } \\
\text { control of laminated glass) }\end{array}$ & $\mathrm{P}+\mathrm{M}$ & $\begin{array}{l}\operatorname{NORM}(43.4,5.54) \\
35.5 * \operatorname{ERLA}(2.75,2)\end{array}$ \\
\hline $\begin{array}{l}\text { Applying tape (Application of tape on glass } \\
\text { edges) }\end{array}$ & $\mathrm{P}$ & $\operatorname{NORM}(23.1,2.52) ; \operatorname{NORM}(24.8,1.44)$ \\
\hline $\begin{array}{l}\text { Mounting frame (Mounting taped glass into } \\
\text { aluminium frame) }\end{array}$ & $\mathrm{P}+\mathrm{M}$ & $\begin{array}{l}\text { UNIF(58.5, 69.5); } \\
\text { TRIA(97.5, 120, 146) }\end{array}$ \\
\hline $\begin{array}{l}\text { Quality control (Separating panels according to } \\
\text { quality group and flaws) }\end{array}$ & $\mathrm{P}$ & TRIA( $(40.5,48,70.5)$ \\
\hline $\begin{array}{l}\text { Junction Box (JB) installation (Installation of JB } \\
\text { to panels) }\end{array}$ & $\mathrm{P}$ & $\operatorname{NORM}(28.6,4.03)$ \\
\hline $\begin{array}{l}\text { Flasher (Checking whether the panel has the } \\
\text { desired power) }\end{array}$ & $\mathrm{P}+\mathrm{M}$ & $19+11 * \operatorname{BETA}(1.44,1.31)$ \\
\hline
\end{tabular}

\subsection{Model validation}

In model validation, the results of the established model are compared with the real system. The company works with 8-hour shifts. In the first part, the usage rates calculated with the working times according to the observations made in the real system, and the corresponding simulation model usage rates of the real system are given in the Table II. The mean and standard deviation of the usage rates were also obtained for statistical validation. The $t$-test was used in the calculation of two independent group tests for the average personnel and machine utilization rate. 
Table II: Personnel or machine utilization of real current system and simulation model.

\begin{tabular}{|l|c|c|c|}
\hline \multirow{2}{*}{ Resource } & \multicolumn{2}{|c|}{ Real Current System } & Simulation Model \\
\cline { 2 - 4 } & Working Time (min) & Utilization (\%) & Utilization (\%) \\
\hline Operator1 & 234 & 49 & 56 \\
Operator2 & 80 & 17 & 3 \\
Lay-up1 machine & 470 & 98 & 98 \\
Lay-up2 machine & 283 & 59 & 63 \\
Lay-up3 machine & 298 & 62 & 61 \\
Lay-up4 machine & 244 & 51 & 42 \\
Soldering Operator1 & 238 & 50 & 44 \\
Soldering Operator2 & 472 & 98 & 97 \\
Mirror control operator1 & 235 & 49 & 45 \\
Mirror control operator2 & 105 & 22 & 19 \\
EL-1 operator & 168 & 35 & 35 \\
EL-2 operator & 117 & 24 & 16 \\
\hline \multicolumn{2}{c}{ Mean } & 51.1 & 48.3 \\
\multicolumn{2}{c}{ STD. } & 26.3 & 29.4 \\
\hline
\end{tabular}

$H_{0}$ : The mean of real current personnel and machine utilization is equal to the mean of model personnel and machine utilization.

$H_{1}$ : The mean of real current personnel and machine utilization is not equal to the mean of model personnel and machine utilization.

Degree of freedom: $12+12-2=22$, Significance level $\alpha=0.05$.

The $t$-table value: $t_{\frac{\alpha}{2} ; 22}= \pm 2.074 \quad$ The test statistic : $\frac{51.1-48.3}{\sqrt{\frac{26.3^{2}}{12}+\frac{29.4^{2}}{12}}}=0.25$

Comment: The test statistic of 0.25 was between -2.074 and 2.074 while the $p$-value of the $t$-test was 0.805 at 95 percent of confidence interval which was higher than 0.05 . It is considered that the $95 \%$ confidence level, the mean of real personnel and machine utilization is equal to the mean of model personnel and machine utilization. Therefore, the $H_{0}$ hypothesis cannot be rejected. In other words, there is no statistically significant difference between the real system and the simulation model, and the model represents the real system.

Table III: Results of hypothesis testing.

\begin{tabular}{|l|c|c|c|}
\hline Variable & Actual result (\%) & Model result (\%) & $p$-value \\
\hline First part personnel and machines & 51.11 & 48.30 & 0.805 \\
Second part personnel and machines & 98.40 & 99.50 & 0.146 \\
Third part personnel and machines & 38.50 & 33.00 & 0.477 \\
\hline
\end{tabular}

The results obtained for all sections are given in Table III, and $p$-value of each parameter was higher than 0.05 at the $95 \%$ confidence interval. Therefore, there is no statistically significant difference between the real current system and the simulation model. As a result, the simulation model is considered to be valid.

\subsection{The first section current model simulation and proposed scenarios}

\section{- First scenario}

This scenario was developed according to the first section current model outputs. A new soldering line was created. In total, 3 soldering lines and 6 conveyors were used. $1^{\text {st }}$ Soldering line 1 conveyor, $2^{\text {nd }}$ Soldering line 1 conveyor, $3^{\text {rd }}$ Soldering line 4 conveyors.

- $\underline{\text { Second scenario }}$

Compared to the soldering line in the current model, two soldering lines were added. In total, 4 soldering lines and 6 conveyors were used. $1^{\text {st }}$ Soldering line 1 conveyor, $2^{\text {nd }}$ Soldering line 1 conveyor, $3^{\text {rd }}$ Soldering line 1 conveyor, $4^{\text {th }}$ Soldering line 3 conveyors. 
When the current model and the model with 4 soldering stations were compared, it was obvious that the third and fourth soldering lines added to the model in the first and second scenarios increased the output number and resource utilization rates. A new machine system was not used in the proposed models. The positions of the 6 conveyors in the current model were changed.

Comparing existing and VVM, an increase of $38.5 \%$ in the number of outputs in the first VVM and $32.93 \%$ in the second VVM were achieved. These results were obtained only by changes in the conveyor system in the production line. Improper design of the conveyor layout caused bottlenecks in the current model, causing serious reductions in the number of outputs. It was determined that the first scenario was more appropriate in terms of the number of outputs. Comparison of current model and proposed model results in terms of machine and personnel usage rates are shown in Table IV.

Table IV: Comparison of models' results in terms of machine and personnel usage rates for $1^{\text {st }}$ section.

\begin{tabular}{|lc|lc|lc|}
\hline \multicolumn{2}{|c|}{ Current Model } & \multicolumn{2}{c|}{ First Scenario } & \multicolumn{2}{c|}{ Second Scenario } \\
\hline Total number of outputs & 1 011 ea. & Total number of outputs & 1 401 ea. & Total number of outputs & 1344 ea. \\
\hline Resource & Usage rate & Resource & Usage rate & Resources & Usage rate \\
\hline Operator1 & 0.56 & Operator1 & 0.77 & Operator1 & 0.73 \\
Operator2 & 0.03 & Operator2 & 0.07 & Operator2 & 0.07 \\
Lay-up1 machine & 0.98 & Lay-up1 machine & 0.98 & Lay-up1 machine & 0.98 \\
Lay-up2 machine & 0.63 & Lay-up2 machine & 0.69 & Lay-up2 machine & 0.60 \\
Lay-up3 machine & 0.61 & Lay-up3 machine & 0.67 & Lay-up3 machine & 0.61 \\
Lay-up4 machine & 0.42 & Lay-up4 machine & 0.97 & Lay-up4 machine & 0.97 \\
Soldering operator1 & 0.44 & Soldering operator1 & 0.99 & Soldering operator1 & 0.98 \\
Soldering operator2 & 0.97 & Soldering operator2 & 0.95 & Soldering operator2 & 0.60 \\
& & Soldering operator3 & 0.89 & Soldering operator3 & 0.61 \\
& & & & Soldering operator4 & 0.97 \\
Mirror control operator1 & 0.45 & Mirror control operator1 & 0.35 & Mirror control operator1 & 0.39 \\
Mirror control operator2 & 0.19 & Mirror control operator2 & 0.52 & Mirror control operator2 & 0.44 \\
EL1-1 operator & 0.35 & EL1-1 operator & 0.27 & EL1-1 operator & 0.31 \\
EL1-2 operator & 0.16 & EL1-2 operator & 0.45 & EL1-2 operator & 0.38 \\
\hline
\end{tabular}

\subsection{The second section current model simulation and proposed scenarios}

The results according to the current model are given in Table III.

When the results were examined according to the current model in the first section, the machine capacities were sufficient. However, the machine capacities were insufficient according to the VVM results. Therefore, a VVM was designed for the second section.

- $\underline{\text { The proposed scenario }}$

A new laminator was added into the model. The aim was to increase the number of outputs with the added laminator. Comparison of current model and proposed model results in terms of machine usage rates are shown in Table V.

Table V: Comparison of models' results in terms of machine usage rates for $2^{\text {nd }}$ section.

\begin{tabular}{|l|c|c|}
\hline Total number of outputs & 1288 ea. & 1608 ea. \\
\hline Resource & Usage rate & Usage rate \\
\hline Laminator1 & 1.00 & 1.00 \\
Laminator2 & 1.00 & 1.00 \\
Laminator3 & 1.00 & 1.00 \\
Laminator4 & 0.98 & 0.98 \\
Laminator5 & & 0.97 \\
\hline
\end{tabular}


After the addition of Laminator5, 1608 panels were produced according to the simulation model. In this section, a new laminating machine was added to increase the output number. With the addition of this machine, a $24.84 \%$ increase in the output number was achieved.

\subsection{The third section current model simulation and proposed scenarios}

When the results were examined, 38 pallets were produced. Since there were 31 products in one palette, a total of 1178 panels were produced. Several different scenario model simulations were made based on these results. Assuming that there were inputs from 4 laminating machines: - The model was reconfigured by changing the line where the EL2 machine group was located.

- The model was reconfigured by using 1 edge-cutting operator and 1 EL2 machine.

- The model was reconfigured by using 1 edge-cutting operator, 1 EL2 machine, 1 tape operator, 1 frame machine and 1 quality control operator.

Assuming that there are inputs from 5 laminating machines:

- The model was reconfigured by using 1 edge-cutting operator, 1 EL2 machine, 1 tape operator and 1 control operator.

The first scenario

Comparing the outputs of the current model with the first VVM, the output number increased by 1 pallet. Changes in machine usage rates were observed. No changes were made to the number of personnel in this model. Without making any changes in the number of machines and personnel, only the positions of the machines and conveyors were changed, and there was an improvement in the output number.

The second scenario

This model was designed by using 1 edge-cutting operator, 1 EL2 machine and 1 frame machine. Comparing the results, the output number increased by 2 pallets when the edge-cutting operator and EL2 machine were removed from the system. Moreover, machine usage rates increased. Since the machines were removed, 2 personnel were removed as well. Thus, the system was improved. As a result, improvements were achieved by both the increase in the output number and a decrease in the required number of personnel.

The third scenario

This model was designed using 1 edge-cutting operator, 1 EL2 machine, 1 tape operator and a quality control operator. Comparing the system results, the output number increased by 2 pallets when the edge-cutting operator, EL2 machine, tape operator, frame machine and 2 operators, and the quality control operator were removed. Consequently, the system was improved because of the removal from the system of the machines and 6 personnel operating those machines. In addition, it was concluded that the usage rates of other machine operators increased when these machines and operators were removed from the system. As a result, both the output number increased and the labour cost decreased, which led to a decrease in the required number of personnel.

The fourth scenario

In this scenario, it was assumed that there were inputs from 5 laminators. The time between outputs produced by the VVM was used in this scenario. One edge-cutting operator, 1 EL2 machine and operator and 1 tape operator were removed from the system and the results were compared with the current model. Comparing the results, more panels enter the system compared to the current model because of the panels produced by the fifth laminator. While more panels enter the system, it is also observed that when the edge-cutting operator, EL2 machine and tape operator were removed, the output number increased by 12 pallets. When the machines and operators were removed from the system model, it was concluded that usage rates of other machine operators increased. As a result, both the number of outputs increased and the labour cost decreased, which led to a decrease in the required number of personnel. Simulation results according to the data in the third section are given in Table VI. 
Kilic, Erkayman: A Simulation Approach for Transition to JIT Production System

Table VI: Comparison of models' results in terms of machine and personnel usage rates for $3^{\text {rd }}$ section.

\begin{tabular}{|lccccc|}
\hline Total number of outputs & 38 palettes & 39 palettes & 40 palettes & 40 palettes & 50 palettes \\
\hline Resource & Usage rate & Usage rate & Usage rate & Usage rate & Usage rate \\
\hline Edge-cutting operator1 & 0.04 & 0.08 & 0.16 & 0.16 & 0.20 \\
Edge-cutting operator2 & 0.13 & 0.09 & & & \\
EL2-1 machine & 0.16 & 0.31 & 0.62 & 0.62 & 0.78 \\
EL2-2 machine & 0.49 & 0.33 & & & \\
Tape operator1 & 0.18 & 0.15 & 0.11 & & \\
Tape operator2 & 0.19 & 0.21 & 0.25 & 0.35 & 0.44 \\
Frame machine1 & 0.76 & 0.69 & 0.54 & & 0.60 \\
Frame machine2 & 0.52 & 0.57 & 0.65 & 0.97 & 0.60 \\
Control operator1 & 0.43 & 0.47 & 0.57 & & 0.50 \\
Control operator2 & 0.33 & 0.30 & 0.23 & 0.81 & 0.50 \\
Junction box instalment & 0.39 & 0.40 & 0.50 & 0.50 & 0.51 \\
operator & 0.34 & 0.35 & 0.36 & 0.35 & 0.44 \\
Flasher machine & & & & & \\
\hline
\end{tabular}

Four different scenarios were considered in this section. The first three VVM inputs were taken from the results of the second section current model, while the fourth VVM inputs were taken from the results of the second section VVM. There were no machines or personnel added to the system. A $2.63 \%$ increase in the number of outputs was achieved in the first VVM. Also a $5.26 \%$ increase in the number of outputs and 2 less personnel were used in the second VVM, and therefore, an improvement in labour costs was achieved in the second VVM. A $5.26 \%$ increase in the number of outputs and 7 less personnel were used in the third VVM, and an increase of $31.58 \%$ and 3 less personnel were used in the fourth VVM. Thus, an improvement in labour costs was achieved in the fourth VVM.

Based on the evaluation of the system before the simulation modelling was performed, many bottlenecks were observed in the manufacturing process. After the model was created, it was found that there was enough raw material input to produce 1851 products in the system while 1178 products were being produced. With the changes have been made in the scenarios, 372 semi-products were transformed to finished products and 1550 products have been produced by applying best proposed model. A significant increase in usage rates was observed. This ultimately led to a reduction in WIP and an increase in the total number of finished products.

\section{CONCLUSION}

In this study, the aim was to reduce the amount of accumulated WIP and to improve the production line by using JIT, one of the solar panel lean manufacturing methods. For this reason, the lean manufacturing method has been the focus of this study. The results were evaluated by using the simulation method to apply JIT, a lean manufacturing method, to reduce the amount of WIP inventory and to see the results, since it is very difficult to change the production line in real life. The factory production line of a solar panel manufacturer was modelled in a computer environment. The simulation model was run by determining the distributions of the data obtained from the existing system. After the model was tested with real system data, different VVM were created by adding and changing the positions, or removing the workbenches, at the points where WIP was found in the production line. VVM and the current model were compared. As a result, changes in machine usage rates and the number of final products were determined. While modelling, the production line was divided into three sections. An increase was achieved when the results were compared in terms of the number of products. 
This study was carried out for the purpose of working without inventory by applying the JIT method to reduce WIP inventory and increase operational efficiency during manufacture. According to simulation results used for the application, the number of finished products and machine usage rates increased compared to the current model. In the current model, 1178 products are produced, corresponding to 38 pallets. Among the proposed scenarios, the first model in the first part, the second model in the second part and the fourth model in the third part fit the purpose of the study best. According to these scenarios, 1550 products are produced, corresponding to 50 pallets. The decrease in WIP inventory and the increase in the utilization of personnel and machinery are the most important factors for the improvement in the finished product quantity. Moreover, since the personnel for workbenches removed were no longer necessary, the personnel expenses were also reduced in the VVM. In addition, finished product will wait less in the warehouse, the delivery time of the products will be shorter, customers will be given more accurate deadlines, and less finished product storage will be needed. Excess raw material inventory in the warehouse will be prevented, raw material cycle time will be shortened, less raw material storage space will be required, the value potential of manufacturing products with the features desired by the customer will increase, there will be a more rapid response to changing customer demand, purchase decisions will be made more accurately, and resources otherwise spent on raw material purchase can be used in another way. It was observed that the revised production produced many benefits that affected the whole system positively: WIP inventory decreased, production speed increased as semi-finished products incurred no waiting time, machinery and labour usage rates increased, machinery, labour, energy and space costs decreased and productivity increased. In addition, thanks to the proposed VVM, information was delivered that assisted investment management and production line revision decisions.

Several important difficulties were encountered during this work. The first is the simulation of the real system by calculating the processing times made with time study of personnel and machines during production. In other words, it is the correct observation of the data and transferring all the details to the simulation model as in real life. Secondly, machine failures during production, machine and personnel downtime due to material delays, different customer orders on the production line, and changes in machine settings during the transition to different product types have led to restrictions in the system. Therefore, future research plan which include consideration of more data-driven approach should be taken into account.

\section{REFERENCES}

[1] Patalas-Maliszewska, J.; Krebs, I. (2016). A model of the tacit knowledge transfer support tool: CKnow-board, Dregvaite, G.; Damasevicius, R. (Eds.), Information and Software Technologies: Communications in Computer and Information Science, Springer, Cham, 30-41, doi:10.1007/9783-319-46254-7_3

[2] Parker, W. S. (2020). Evidence and knowledge from computer simulation, Erkenntnis, Online first, 18 pages, doi:10.1007/s10670-020-00260-1

[3] El-Khalil, R. (2015). Simulation analysis for managing and improving productivity: A case study of an automotive company, Journal of Manufacturing Technology Management, Vol. 26, No. 1, 36-56, doi:10.1108/JMTM-03-2013-0024

[4] Kliment, M.; Trebuna, P.; Pekarcikova, M.; Straka, M.; Trojan, J.; Duda, R. (2020). Production efficiency evaluation and products' quality improvement using simulation, International Journal of Simulation Modelling, Vol. 19, No. 3, 470-481, doi:10.2507/IJSIMM19-3-528

[5] Kłos, S.; Patalas-Maliszewska, J. (2015). Throughput analysis of automatic production lines based on simulation methods, Jackowski, K.; Burduk, R.; Walkowiak, K.; Wozniak, M.; Yin, H. (Eds.), Intelligent Data Engineering and Automated Learning (IDEAL 2015), Springer, Cham, 181-190, doi:10.1007/978-3-319-24834-9_22 
[6] Lee, D.-H.; Lee, C.-H.; Choi, S.-H.; Kim, K.-J. (2019). A method for wafer assignment in semiconductor wafer fabrication considering both quality and productivity perspectives, Journal of Manufacturing Systems, Vol. 52, Part A, 23-31, doi:10.1016/j.jmsy.2019.05.006

[7] Tvrdon, L.; Fedorko, G. (2020). Usage of dynamic simulation in pressing shop production system design, International Journal of Simulation Modelling, Vol. 19, No. 2, 185-196, doi:10.2507/ IJSIMM19-2-494

[8] Abolhassani, A.; Harner, E. J.; Jaridi, M. (2019). Empirical analysis of productivity enhancement strategies in the North American automotive industry, International Journal of Production Economics, Vol. 208, 140-159, doi:10.1016/j.ijpe.2018.11.014

[9] Jakubovskis, A. (2017). Flexible production resources and capacity utilization rates: A robust optimization perspective, International Journal of Production Economics, Vol. 189, 77-85, doi:10.1016/j.ijpe.2017.03.011

[10] Li, L. (2018). A systematic-theoretic analysis of data-driven throughput bottleneck detection of production systems, Journal of Manufacturing Systems, Vol. 47, 43-52, doi:10.1016/ j.jmsy.2018.03.001

[11] Onofrejova, D.; Janekova, J.; Grincova, A.; Soltysova, Z. (2020). Simulation and evaluation of production factors in manufacturing of fireplaces, International Journal of Simulation Modelling, Vol. 19, No. 1, 77-88, doi:10.2507/IJSIMM19-1-504

[12] Yang, S. L.; Xu, Z. G.; Wang, J. Y. (2019). Modelling and production configuration optimization for an assembly shop, International Journal of Simulation Modelling, Vol. 18, No. 2, 366-377, doi:10.2507/IJSIMM18(2)CO10

[13] Tiacci, L. (2015). Simultaneous balancing and buffer allocation decisions for the design of mixedmodel assembly lines with parallel workstations and stochastic task times, International Journal of Production Economics, Vol. 162, 201-215, doi:10.1016/j.ijpe.2015.01.022

[14] Li, H.; Gui, C.; Xiao, K. (2018). Simulation of multivariate scheduling optimization for open production line based on improved genetic algorithm, International Journal of Simulation Modelling, Vol. 17, No. 2, 347-358, doi:10.2507/IJSIMM17(2)CO9

[15] Supsomboon, S.; Vajasuvimon, A. (2016). Simulation model for job shop production process improvement in machine parts manufacturing, International Journal of Simulation Modelling, Vol. 15, No. 4, 611-622, doi:10.2507/IJSIMM15(4)3.352

[16] Pekarcikova, M.; Trebuna, P.; Kliment, M.; Kral, S. (2021). Simulation testing of the e-kanban to increase the efficiency of logistics processes, International Journal of Simulation Modelling, Vol. 20, No. 1, 134-145, doi:10.2507/IJSIMM20-1-551

[17] Takakuwa, S.; Yang, W.; Nagatsuka, H. (2018). Learning the procedure on takt production of TPS by methods engineering and simulation, International Journal of Simulation Modelling, Vol. 17, No. 4, 633-642, doi:10.2507/IJSIMM17(4)452

[18] Supsomboon, S.; Varodhomwathana, T. (2017). Robot and plant simulation for automotive part production process design: a case study, International Journal of Simulation Modelling, Vol. 16, No. 4, 617-629, doi:10.2507/IJSIMM16(4)5.397

[19] Das, K. (2018). Integrating lean systems in the design of a sustainable supply chain model, International Journal of Production Economics, Vol. 198, 177-190, doi:10.1016/ j.ijpe.2018.01.003

[20] Abreu-Ledón, R.; Lujan-Garcia, D. E.; Garrido-Vega, P.; Escobar-Perez, B. (2018). A metaanalytic study of the impact of Lean Production on business performance, International Journal of Production Economics, Vol. 200, 83-102, doi:10.1016/j.ijpe.2018.03.015

[21] Kovács, G. (2020). Combination of Lean value-oriented conception and facility layout design for even more significant efficiency improvement and cost reduction, International Journal of Production Research, Vol. 58, No. 10, 2916-2936, doi:10.1080/00207543.2020.1712490

[22] Erkayman, B. (2019). Transition to a JIT production system through ERP implementation: a case from the automotive industry, International Journal of Production Research, Vol. 57, No. 17, 5467-5477, doi:10.1080/00207543.2018.1527048

[23] Gundogar, E.; Yilmaz, A.; Erkayman, B. (2014). A solution approach to a synchronisation problem in a JIT production system, Production Planning \& Control, Vol. 25, No. 12, 990-998, doi: $10.1080 / 09537287.2013 .794984$ 